\title{
COMUNICAÇÃO
}

\section{AVALIAÇÃO DA QUALIDADE MICROBIOLÓGICA DE HORTALIÇAS MINIMAMENTE PROCESSADAS}

\author{
Microbiological quality evaluation minimally processed vegetables
}

\author{
Josiane Fernanda Metler Tresseler ${ }^{1}$, Evânia Altina Teixeira de Figueiredo ${ }^{2}$, Raimundo Wilane de Figueiredo ${ }^{3}$, \\ Terezinha Feitosa Machado ${ }^{4}$, Camila Martins Delfino ${ }^{5}$, Paulo Henrique Machado de Sousa ${ }^{6}$
}

\begin{abstract}
RESUMO
A microbiota é um fator de grande importância na qualidade e conservação de vegetais minimamente processados. Muitos microrganismos podem afetar adversamente a qualidade e a segurança desses produtos, considerando que microrganismos patogênicos, que normalmente não estariam presentes, passam a compor a microbiota contaminante decorrente do manuseio a que são submetidos. Objetivou-se, neste trabalho, determinar a qualidade microbiológica de hortaliças, anterior e posteriormente ao processo de sanitização, como também o período final da vidade-prateleira dos produtos sanitizados, avaliando-se a presença de Listeria sp., Listeria monocytogenes e Salmonella sp. Foram analisadas amostras de agrião, alface, cenoura ralada, espinafre, repolho verde ralado e rúcula minimamente processados. As amostras não sanitizadas foram analisadas no dia da coleta, e as sanitizadas analisadas a 1, 5 e 8 dias após o processamento, a fim de determinar a condição microbiológica dos produtos. As hortaliças foram armazenadas sob temperatura de $5^{\circ} \mathrm{C}$. Salmonella sp. foi detectada em $12,7 \%$ das amostras, enquanto $L$. monocytogenes não foi encontrada em nenhuma delas, embora outras espécies de Listeria tenham sido isoladas de alface e cenoura. A presença de Salmonella sp. tornaram 16 amostras impróprias para o consumo humano, de acordo com a RDC nº 12 .
\end{abstract}

Termos para indexação: Hortaliças, microbiologia, processamento mínimo.

\section{ABSTRACT}

The microbiota is a factor of great importance to the quality and conservation of minimally processed vegetables. Many microorganisms may adversely affect the quality and safety of these products, considering that normally present pathogenic microorganisms may eventually compose the polluting microbiota whenever being submitted to handling. This work aimed to determine both: vegetable microbiologic quality, prior and post-sanitization process as well as products post-sanitization shelf-life expiring date, while the presence of Listeria sp., Listeria monocytogenes and Salmonella sp. was evaluated. The minimally processed vegetables samples analyzed were watercress, lettuce, grated carrot, spinach, grated green cabbage and rucula. The non-sanitized samples were analyzed on the first harvesting day (day 1), and the sanitized ones were analyzed at 1,5 and 8 days after being processed in order to determine the product microbiological state. The vegetables were stored under a temperature of $5^{\circ} \mathrm{C}$. Salmonella sp. was detected in $12.7 \%$ of the samples, while L. monocytogenes was not found in any of them, though other species of Listeria were isolated from lettuce and carrot. According to the $\mathrm{RDC} \mathrm{n}^{\mathrm{o}} 12$, the presence of Salmonella sp. rendered 16 samples as being inappropriate for human consumption.

Index terms: Vegetables, microbiology, minimally processed.

\section{(Recebido em 25 de janeiro de 2007 e aprovado em 8 de julho de 2008)}

As hortaliças minimamente processadas (HMP) surgiram como uma interessante alternativa para o consumidor que não tem tempo de preparar sua refeição ou mesmo não gosta de fazê-lo. Em vários países, verifica- se que esses produtos estão sendo oferecidos nos formatos mais variados, sempre visando à agregação de valor e comodidade do consumidor (CANDEL, 2001; MORETTI, 2004).

\footnotetext{
1Engenheira de Alimentos, Mestre em Ciência e Tecnologia de Alimentos - Departametno de Tecnologia de Alimentos/DTA - Centro de Ciências Agrárias/ CCA - Universidade Federal do Ceará/UFC - Campus do Pici - Cx. P. 12168 - 60356-000 - Fortaleza, CE - josiane_tresseler@yahoo.com.br 2Bióloga, Doutora em Microbiologia de Alimentos, Professora - Departametno de Tecnologia de Alimentos/DTA - Centro de Ciências Agrárias/CCA Universidade Federal do Ceará/UFC - Campus do Pici - Cx. P. 12168 - 60356-000 - Fortaleza, CE - evania@ufc.br

${ }^{3}$ Engenheiro Agrônomo, Doutor em Ciência de Alimentos - Departametno de Tecnologia de Alimentos/DTA - Centro de Ciências Agrárias/CCA Universidade Federal do Ceará/UFC - Campus do Pici - Cx. P. 12168 - 60356-000 - Fortaleza, CE - figueira@ufc.br - Bolsista Nível 2 do CNPq ${ }^{4}$ Engenheira de Alimentos, Doutora em Bioquímica - Embrapa Agroindústria Tropical/CNPAT - Rua Doutora Sara Mesquita, 2270 - Planalto do Pici 60511-110 - Fortaleza, CE - tele@cnpat.embrapa.br

${ }^{5}$ Engenheira de Alimentos - Departametno de Tecnologia de Alimentos/DTA - Centro de Ciências Agrárias/CCA - Universidade Federal do Ceará/UFC Campus do Pici - Cx. P. 12168 - 60356-000 - Fortaleza, CE - millamartins@yahoo.com.br

${ }^{6}$ Químico, Doutor em Ciência e Tecnologia de Alimentos - Departametno de Tecnologia de Alimentos/DTA - Centro de Ciências Agrárias/CCA Universidade Federal do Ceará/UFC - Campus do Pici - Cx. P. 12168-60356-000 - Fortaleza, CE - phenriquemachado@gmail.com - Bolsista DCR do CNPq
} 
As hortaliças e frutas minimamente processados oferecem inúmeros benefícios como: redução do tempo de preparo da refeição, maior padronização e qualidade, maior acesso a frutas e hortaliças mais saudáveis, menor espaço para armazenagem, embalagem de armazenamento fácil e redução do desperdício (CENCI, 2000), além de fornecer uma grande variedade de vitaminas, minerais e outros fitoquímicos, que são importantes para a saúde humana (TOURNAS, 2005).

De acordo com o International Fresh-Cut Produce Association (IFPA, 2001), produtos minimamente processados são frutas ou hortaliças que são modificadas fisicamente, mas que mantêm o seu estado fresco. Assim, é um produto fresco, tornado conveniente, com qualidade e segurança.

As etapas através das quais as hortaliças são minimamente transformadas são basicamente: pré-seleção, classificação, lavagem, corte, sanitização, enxágüe, centrifugação, embalagem e armazenamento refrigerado (SILVA \& FERNANDES, 2003).

A qualidade microbiológica dos alimentos minimamente processados está relacionada à presença de microrganismos deteriorantes que irão influenciar as alterações sensoriais do produto durante sua vida útil. Contudo, a maior preocupação está relacionada com sua segurança, não apresentando contaminação por agentes químicos, físicos e microbiológicos em concentrações prejudiciais à saúde (VANETTI, 2004).

A microbiota é um fator de grande importância na qualidade e conservação de vegetais minimamente processados. Muitos microrganismos podem afetar adversamente a qualidade e a segurança desses produtos, considerando que microrganismos patogênicos que, normalmente, não estariam presentes podem passar a fazer parte da microbiota contaminante decorrentes do manuseio a que são submetidos (ROSA \& CARVALHO, 2000). Portanto, constata-se a necessidade de que a produção de hortaliças minimamente processadas deva ser regulada pelas boas práticas de fabricação (BPF), visando minimizar a contaminação (FDA, 2001).

Objetivou-se, no presente estudo, avaliar a qualidade microbiológica em hortaliças minimamente processadas comercializadas na cidade de Fortaleza-CE, através da verificação da pesquisa de Listeria sp., Listeria monocytogenes e Salmonella sp.

Amostras de agrião, alface, cenoura ralada, espinafre, repolho verde ralado e rúcula minimamente processados foram obtidas em uma indústria de processamento mínimo localizada no estado do Ceará, sendo imediatamente transportadas em caixas térmicas com blocos de gelo até o laboratório de microbiologia para realização das análises.
Foram destinadas ao processamento bateladas de 4 a $5 \mathrm{~kg}$ de cada uma das hortaliças citadas, das quais foram retiradas, ao acaso, cinco frações de 50 gramas, compondo uma unidade amostral de 250 gramas.

Analisaram-se 126 amostras de hortaliças, sendo avaliadas seis tipos de hortaliças, com sete amostras do produto in natura, sete do produto logo após a sanitização e sete do produto sanitizado analisado ao final do período de armazenamento, indicado pelo fornecedor, de acordo com a Tabela 1.

Tabela 1 - Hortaliças minimamente processadas e seus respectivos dias de armazenamento a $5^{\circ} \mathrm{C}$.

\begin{tabular}{cc}
\hline $\begin{array}{c}\text { Hortaliça Minimamente } \\
\text { Processada }\end{array}$ & $\begin{array}{c}\text { Dias de } \\
\text { Armazenamento }\end{array}$ \\
\hline Agrião & 8 \\
Alface & 8 \\
Cenoura ralada & 5 \\
Espinafre & 8 \\
Repolho verde ralado & 5 \\
Rúcula & 5 \\
\hline
\end{tabular}

As amostras in natura foram coletadas ao final das etapas de pré-lavagem (agrião, alface, espinafre e rúcula) e ralagem (cenoura e repolho). As amostras sanitizadas foram coletadas após o procedimento de centrifugação e embalagem, utilizado no processamento (Figura 1). As amostras dos produtos in natura, bem como as sanitizadas, em seu tempo inicial de vida-de-prateleira, foram analisadas no mesmo dia da coleta. As amostras também foram avaliadas após o final do armazenamento refrigerado a $5^{\circ} \mathrm{C}$.

\section{Detecção de Salmonella sp.}

As análises foram realizadas de acordo com Andrews $\&$ Hammack (2003). Foram adicionados às 25 gramas de amostra $225 \mathrm{~mL}$ de caldo lactosado. Em seguida, a mistura foi incubada à temperatura de $35^{\circ} \mathrm{C}$, por um período de 24 horas. Após o período de incubação, seguiu-se a fase de enriquecimento seletivo em Rappaport-Vassiliadis e caldo tetrationato, à temperatura de $42^{\circ} \mathrm{C} \mathrm{e} 35^{\circ} \mathrm{C}$ por 24 horas, respectivamente. Completadas 24 horas, o isolamento de Salmonella sp. foi realizado em ágar bismuto sulfito, ágar xilose lisina desoxicolato e ágar entérico de Hecktoen, incubados a $35^{\circ} \mathrm{C}$ por $24-48$ h. Para confirmação preliminar, foi removida uma porção da massa celular do centro de colônias típicas e inoculada em tubos contendo ágar lisina ferro (LIA) e ágar tríplice açúcar ferro (TSI). Procedeu-se à incubação, sob uma temperatura de $35^{\circ} \mathrm{C}$, por um período de 24 horas. Após os procedimentos acima descritos, foi realizada a etapa de identificação, utilizando-se testes como os de urease, indol, vermelho de metila, Voges Proskauer, citrato e o teste sorológico somático polivalente. 


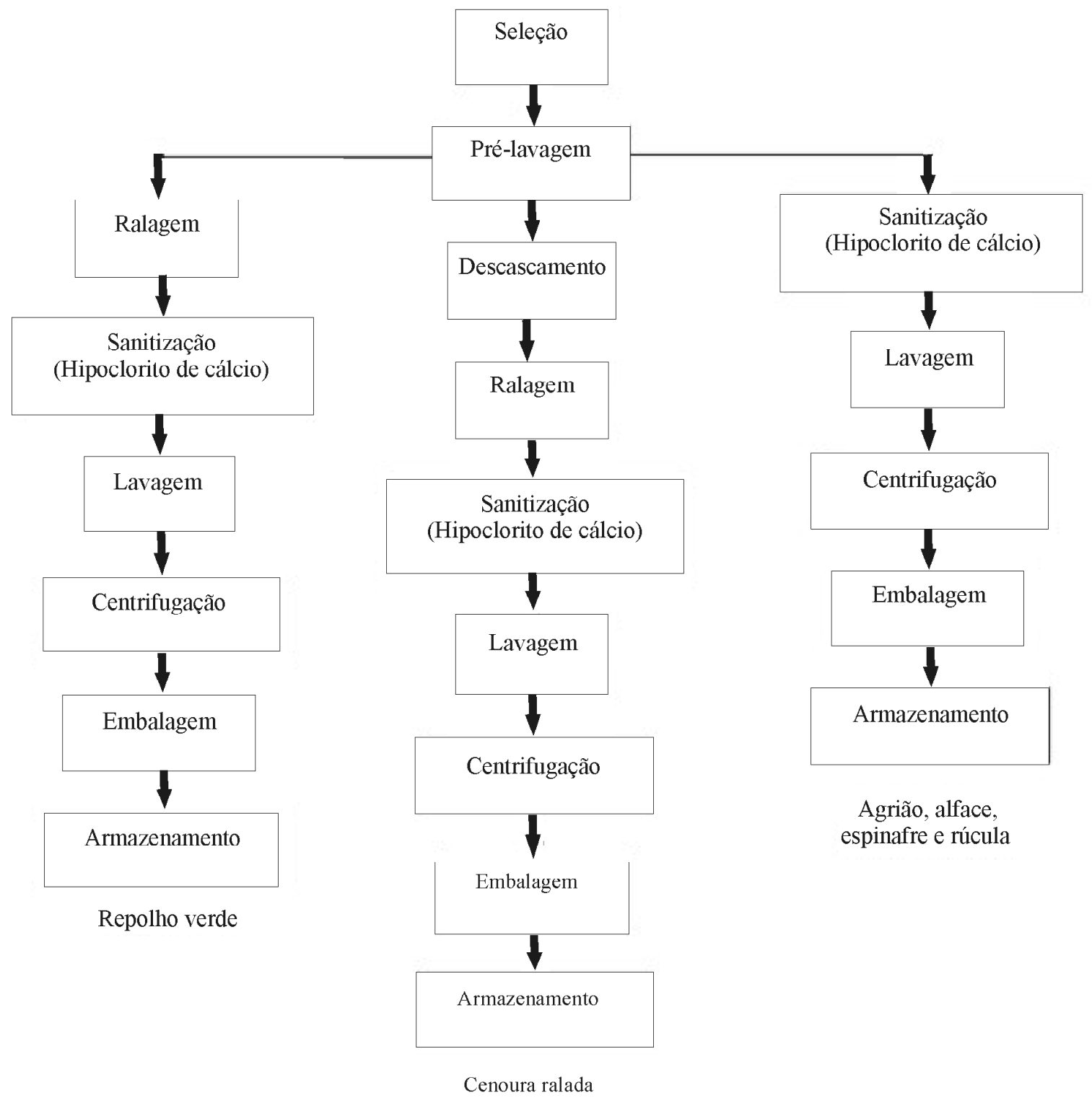

Figura 1 - Fluxograma do processamento de hortaliças minimamente processadas.

\section{Detecção de Listeria sp. e Listeria monocytogenes}

As análises foram realizadas de acordo com Pagotto et al. (2001). Foram adicionados à unidade analítica $225 \mathrm{~mL}$ de caldo enriquecimento de Listeria (LEB), incubando-se em seguida sob temperatura de $30^{\circ} \mathrm{C}$, por um período total de 48 horas. Após períodos de incubação de 24 e 48 horas, retirou-se uma alíquota de $0,1 \mathrm{~mL}$ da cultura em $\mathrm{LEB}$, e adicionou-se em caldo fraser modificado. $\mathrm{O}$ mesmo foi incubado sob temperatura de $35^{\circ} \mathrm{C}$ por 24 horas. Atingidas 20 horas de incubação, o tubo foi agitado e reincubado para completar o período de 24 horas. Os tubos contendo caldo fraser modificado foram avaliados quanto à mudança de cor do meio para preta, marrom escuro ou verde escuro. Para isolamento foram utilizados ágar oxford (OXA) e ágar palcam (PAL), incubados à temperatura de $35^{\circ} \mathrm{C}$ por 24 horas. Após os procedimentos acima descritos, foi realizada a etapa de identificação de Listeria sp e Listeria monocytogenes, utilizando-se testes como os de motilidade, hemólise, vermelho de metila, Voges Proskauer, catalase, fermentação dos açúcares rhamnose, xilose e manitol. 
Da totalidade de amostras analisadas $(\mathrm{n}=126$ amostras), $12,7 \%$ apresentaram contaminação com Salmonella sp.

Observou-se que quatro amostras de agrião "in natura" apresentaram-se contaminadas com Salmonella sp. (Figura 2). Uma dessas amostras, mesmo após o processo de sanitização, ainda permaneceu contaminada pelo patógeno, porém, a presença do mesmo só foi detectada após o período de armazenamento por 8 dias, à temperatura de $5^{\circ} \mathrm{C}$. Esse fato ocorreu, provavelmente, por dano causado às células pela ação do produto sanitizante, tendo sido dificultada a sua recuperação pela metodologia empregada ou pelo fato do número de cepas ser inferior ao nível de detecção obtido pelo método. Ryser \& Marth (1991) justificam que muitos caldos de enriquecimento e meios de plaqueamento falham em favorecer o reparo e/ou crescimento de bactérias injuriadas, frequentemente presentes em alimentos processados.

Uma amostra de agrião minimamente processado sanitizado, apresentou-se contaminada com Salmonella sp. (Figura 1), porém, em seu estado "in natura", anteriormente à sanitização, não apresentou contaminação. Portanto, a ocorrência de Salmonella sp. no agrião minimamente processado sanitizado, pode ser atribuída à contaminação cruzada ocorrida durante o processamento. Segundo Nguyen-The \& Carlin (1994), equipamentos, utensílios, embalagens e manipuladores no processamento mínimo de vegetais, são fontes potenciais de contaminação.

Para alface e repolho minimamente processados foi observada contaminação em apenas uma amostra "in natura", para ambas as hortaliças (Figura 2). Na amostra após sanitização e ao final do período de armazenamento não foi encontrada contaminação, sendo nesse caso, a sanitização eficiente na remoção do patógeno.

Apenas uma amostra de espinafre "in natura" apresentou contaminação por Salmonella sp., sendo que a mesma amostra sanitizada analisada ao final do armazenamento encontrou-se contaminada com a bactéria (Figura 2). A solução aquosa clorada reduziu o nível dessa espécie sobre espinafre minimamente processado, mas não a eliminou completamente. Outra amostra de espinafre sanitizado apresentou contaminação por Salmonella sp. apenas no período final de armazenamento, fato que permite presumir a ocorrência de não conformidade na aplicação das boas práticas de fabricação (BPF), durante a manipulação. Pirovani et al. (2000), em estudo realizado com espinafre minimamente processado e sanitizado, verificaram que a máxima redução para Salmonella hadar foi de $96 \%$.

Salmonella sp. foi observada em duas amostras de rúcula minimamente processadas "in natura”. A sanitização não proporcionou a eliminação do microrganismo, sendo que as duas amostras, analisadas logo após esse procedimento, permaneceram contaminadas pelo patógeno, mas apenas uma delas apresentou-se contaminada ao final do período de armazenamento de cinco dias, à temperatura de $5^{\circ} \mathrm{C}$.

Patógenos como Salmonella ou Listeria monocytogenes podem ser introduzidos na área de processamento por vários vetores e podem se estabelecer

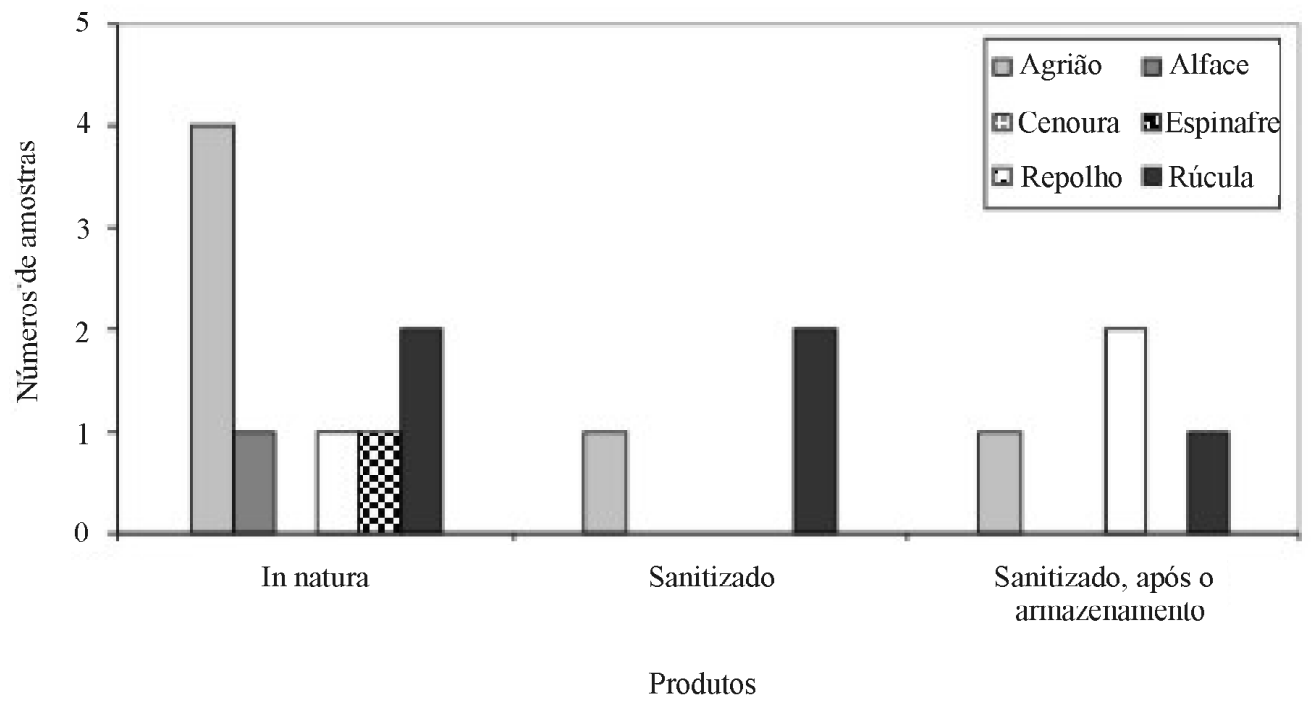

Figura 2 - Número de amostras de hortaliças contaminadas com Salmonella sp. 
e multiplicar, particularmente em locais da área de processamento que são difíceis de limpar e sanitizar, tornando-se focos de contaminação. As condições ambientais as quais os alimentos prontos para o consumo são expostos podem ser uma fonte potencial de patógenos (ICMSF, 2002).

Embora a RDC no 12 de 02 de janeiro de 2001 (BRASIL, 2001), que estabelece o regulamento técnico sobre padrões microbiológicos para alimentos, não caracterize padrões para produtos como hortaliças minimamente processadas, considera-se a similaridade da natureza e do processamento de outro produto caracterizado nessa resolução, como base para o enquadramento de hortaliças minimamente processadas nos padrões microbiológicos estabelecidos. Dessa forma, as hortaliças que apresentaram presença de Salmonella sp. estavam todas impróprias para consumo humano, segundo a RDC n ${ }^{\circ} .12$ de 02 de janeiro de 2001 (BRASIL, 2001), que determina que esse patógeno esteja ausente em porções de $25 \mathrm{~g}$ analisadas.

A bactéria Listeria monocytogenes não foi detectada nas amostras de agrião, alface, cenoura, espinafre, repolho verde e rúcula minimamente processados; porém, segundo Aguado et al. (2004), o isolamento de espécies não patogênicas de Listeria pode ser considerado como um indicador de advertência, que reforça a necessidade de medidas corretivas para evitar contaminação na planta de processamento, utensílios e equipamentos.

Listeria seeligeri e Listeria ivanovii não patogênicas foram detectadas em uma amostra de cenoura ralada ao final do armazenamento de 5 dias a $5^{\circ} \mathrm{C}$, em três amostras de alface, sendo duas amostras "in natura" e uma sanitizada, analisadas ao final do período de armazenamento e em uma amostra de repolho verde ralado "in natura".

Embora a maioria das hortaliças analisadas encontrar-se de acordo com os padrões legais vigentes, para que a segurança alimentar seja garantida, constatouse a grande necessidade de implementar as Boas Práticas de Fabricação (BPF), seguida do programa de Análise de Perigos e Pontos Críticos de Controle (APPCC), visando controlar os perigos que possam ocorrer em todas as etapas da cadeia produtiva.

Algumas amostras de hortaliças in natura, exceto a cenoura ralada, estavam contaminadas com Salmonella sp., sendo veiculo desse patógeno para a área de processamento da indústria.

A presença de Salmonella sp., em algumas amostras de hortaliças após o processo de sanitização e no final do período de armazenamento, indicam um processo de sanitização deficiente e ocorrência de contaminação cruzada.

Não foi detectada a presença de Listeria monocytogenes nas amostras de hortaliças avaliadas antes e após o processamento e armazenamento. Contudo, a contaminação com espécies não patogênicas de Listeria sugere a necessidade de um monitoramento mais efetivo das condições de processo.

A falta de inocuidade microbiológica, em algumas amostras durante o processamento mínimo avaliado, sugere como pontos críticos de controle a recepção das hortaliças in natura e o processo de sanitização.

Todas as amostras contaminadas com Salmonella sp., portanto, são impróprias para o consumo humano.

\section{REFERÊNCIAS BIBLIOGRÁFICAS}

\section{AGUADO, V.; VITAS, A. I.; GARCÍA-JALÓN, I.}

Characterization of Listeria monocytogenes and Listeria innocua from a vegetable processing plant by RAPD and REA. International Journal of Food Microbiology, v. 90, p. 341-347, 2004.

\section{ANDREWS, W. H.; HAMMACK, T. S. Salmonella. Bacteriological Analytical Manual Online, v. 5, p. 1-19, 2003.}

BRASIL. Ministério da Saúde. Resolução n. ${ }^{\mathbf{1}}$ 12, de 2 de janeiro de 2001. Regulamento técnico sobre os padrões microbiológicos para alimentos. Brasília, DF, 2001. Disponível em: <hittp://e-legis.bvs.br/leisref/public home.php>. Acesso em: 10 ago. 2004.

CANDEL, M. J. J. M. Consumers' convenience orientation towards meal preparation: conceptualization and measurement. Appetite, v. 36, p. 15-28, 2001.

CENCI, S. A. Pesquisa em processamento mínimo de hortaliças no Brasil. In: ENCONTRO NACIONAL SOBRE PROCESSAMENTO MÍNIMO DE FRUTAS E HORTALIÇAS, 2., 2000, Viçosa, MG. Anais... Viçosa: UFV, 2000. p. 110.

FOOD AND DRUG ADMINISTRATION. Analysis and evaluation of preventive control measures for the control and reduction/elimination of microbial hazards on fresh and fresh-cut produce. 2001. Disponível em: uwww.fda.govi >. Acesso em: 15 nov. 2004. 
INTERNATIONAL COMMISSION ON

MICROBIOLOGICAL SPECIFICATIONS FOR FOODS.

Microorganisms in foods: microbiological testing in food safety management. New York: Kluwer Academic Plenum, 2002. v. 7, cap. 11, 6362 p.

\section{INTERNATIONAL FRESH-CUT PRODUCE}

ASSOCIATION. Food safety guidelines for the fresh-cut produce industry. 4. ed. [S.1.], 2001. $213 \mathrm{p}$.

MORETTI, C. L. Panorama do processamento mínimo de hortaliças. In: ENCONTRO NACIONAL SOBRE PROCESSAMENTO MÍNIMO DE FRUTAS E HORTALIÇAS, 2004, Viçosa, MG. Resumos... Viçosa: UFV, 2004. p. 1-8.

NGUYEN-THE, C.; CARLIN, F. The microbiology of minimally processed fresh fruits and vegetables. Critical Reviews in Food Science and Nutrition, v. 34, p. 371-401, 1994.

PAGOTTO, F.; DALEY, E.; FARBER, J.; WABURTON, D. Isolation of Listeria monocytogenes from all food and Environmental Samples. Health Products and Food Branch, p. 1-15, 2001.
PIROVANI, D. R.; GÜEMES, D. R.; PENTIMA, J. H. di; TESSI, M. A. Survival of Salmonella hadar after washing disinfection of minimally processed spinach. Letters in Applied Microbiology, v. 31, p. 143-148, 2000.

ROSA, O. O.; CARVALHO, E. P. de. Características microbiológicas de frutos e hortaliças minimamente processados. Boletim SBCTA, Campinas, v. 34, n. 2, p. 84-92, 2000.

RYSER, E. T.; MARTH, E. H. Listeria, listeriosis and food safety. New York: M. Dekker, 1991. 631 p.

SILVA, C. A. B.; FERNANDES, A. R. Projetos de empreendimentos agroindustriais: produtos de origem vegetal. Viçosa: UFV, 2003. v. 2, 459 p.

TOURNAS, V. H. Moulds and yeasts in fresh and minimally processed vegetables, and sprouts. International of Food Microbiology, v. 99, n. 1, p. 71-77, 2005.

VANETTI, M. C. D. Segurança microbiológica em produtos minimamente processados. In: ENCONTRO NACIONAL SOBRE PROCESSAMENTO MINIMO DE FRUTAS E HORTALIÇAS, 3., 2004, Viçosa, MG.

Resumos... Viçosa: UFV, 2004. p. 30-32. 